\title{
TLR5: A prognostic and monitoring indicator for triple-negative breast cancer
}

\author{
Dai Shi $\mathbb{D}^{1}$, Shanshan Zhao $\mathbb{D}^{1}$, Wen Jiang ${ }^{1}$, Chao Zhang ${ }^{1}$, Ting Liang ${ }^{1}$ and Guihua Hou'
}

\begin{abstract}
A novel, highly selective biomarker is urgently needed to predict and monitor triple-negative breast cancer (TNBC) because targeting molecules are not currently available. Although associated with various malignant tumors, the role of toll-like receptor 5 (TLR5) in TNBC remains uncertain. We aimed to define the effects of TLR5 in TNBC to determine whether it could serve as a prognostic and monitoring indicator for TNBC. We established TNBC cell line 4T1 with low TLR5 expression (GFP tag; TLR5 ${ }^{-}$4T1) and with normal TLR5 expression (GFP tag; TLR5 ${ }^{+}$4T1) using lentivirus-shRNATLR5 knockdown transfection and negative lentivirus transfection, respectively. Detected by western blot and gPCR, we found knockdown of TLR5 resulted in decreased expression of TLR5 and E-cadherin and increased expression of $\mathrm{N}$-cadherin, vimentin, fibronectin, TRAF6, SOX2, and Twist1, which were related to EMT (epithelial-mesenchymal transition). In addition, downregulation of TLR5 increased the invasion and migration of 4T1 cells in vitro, which were investigated by CCK-8 and wound healing, as well as transwell assay and colony formation. Furthermore, the metastatic ability of TLR5 ${ }^{-} 4 \mathrm{~T} 1$ cells to the lungs was also increased compared to TLR5 ${ }^{+} 4 \mathrm{~T} 1$ cells in vivo. To verify the effect of TLR5 as a monitor indicator, mice bearing TLR5 ${ }^{+}$and TLR5 ${ }^{-} 4$ T1 tumors injected with ${ }^{125}$ I-anti-TLR5 mAb or isotype ${ }^{125}$ I-IgG were assessed by whole body phosphor-autoradiography and fluorescence imaging in vivo.

Phosphor-autoradiography of model mice revealed early tumors at 6 days after inoculation with TLR5 ${ }^{+} 4 \mathrm{TT}$, but not $\mathrm{TLR5}^{-}$4T1 cells. Intratumoral accumulation of radioactivity positively correlated with TLR5 expression, and fluorescence imaging in vivo revealed both $\mathrm{TLR}^{+}$and $\mathrm{TLR}^{-} 4 \mathrm{~T} 1$ tumors. Our results suggested that downregulation of TLR5 in TNBC increased tumor invasiveness and EMT expression via TRAF6 and SOX2 pathway and TLR5 could serve as a prognostic and monitoring indicator for TLR5-positive tumors.
\end{abstract}

\section{Introduction}

Membrane-bound toll-like receptors (TLRs) play key roles in innate and adaptive immunity. They are primarily expressed in some types of immunocytes and recognize conserved pathogen-associated molecular patterns (PAMPs) $)^{1-4}$. Various members of the TLR family play diversified roles in cancer progression and development $^{5,6}$. For example, positive TLR3 expression indicates a favorable prognosis for patients with neuroblastoma ${ }^{7}$, and TLR4 overexpression is reduced in squamous cell

\footnotetext{
Correspondence: Guihua Hou (ghhou@sdu.edu.cn)

${ }^{1}$ Key Laboratory for Experimental Teratology of the Ministry of Education and Biomedical Isotope Research Center, School of Basic Medical Sciences,

Shandong University, Jinan, Shandong, China

Edited by A. Stephanou
}

carcinoma of the skin ${ }^{8}$. Unlike other TLRs, TLR5 is not expressed in murine macrophages and conventional dendritic cells ${ }^{9}$, but it is expressed at high levels in some malignancies, such as non-small cell lung cancer $^{10}$ and NK cells within breast cancer ${ }^{11}$. Cancer cell proliferation and tumor growth are inhibited by TLR5 signaling ${ }^{12-14}$, but the underlying mechanism has not been fully elucidated.

Breast cancer is the most common cancer among women, and it is associated with high mortality rates ${ }^{15-17}$. It can be classified into TNBC (triple-negative breast cancer) and non-TNBC subtypes. The TNBC type accounts for $12-24 \%$ of all breast cancers and is more aggressive and prone to metastasis than the non-TNBC type. Current clinical management of breast cancer 
mainly depends on estrogen receptor (ER), progesterone receptor (PR), and human epidermal growth factor receptor 2 (HER2) genes as molecular markers and therapeutic and prognostic indicators. However, targeted diagnoses and therapy are not currently feasible for TNBC because it does not express ER, PR, and HER $2^{18}$. Radical surgery is still the first choice of treatment for breast cancer, even though metastasis usually appears within a few years ${ }^{19}$. Hence, the identification of new monitoring molecular markers and clarifying the underlying mechanisms are critical for improved prognosis for patients with TNBC.

Traditional computed tomography $(\mathrm{CT})$ and magnetic resonance imaging (MRI) in tumor diagnosis and staging mainly reveal anatomic changes, and these are usually found at the later stages ${ }^{20}$. Noninvasive nuclear molecular imaging is a whole-body scanning modality that is based on metabolism and abnormal function. It is a combination of anatomical and functional imaging and is more suitable for the detection and quantitation of target molecules in tumor tissues. Presently, F-18-deoxyglucose $\left({ }^{18} \mathrm{~F}-\mathrm{FDG}\right)$ positron emission tomography/computed tomography (PET/CT) is clinically applied to evaluate tumor metabolism ${ }^{21}$. However, ${ }^{18} \mathrm{~F}$-FDG is not specific, which sometimes results in diagnostic inaccuracy. Hence, identifying more effective molecular targets for tumor prognosis and therapy is critical. Many recent studies have shown that some innate molecules participate in tumor development and prognosis, such as colon cancerassociated transcript2 (CCAT2), metastasis and prognosis $^{22}$ and three miRNAs (potential prognostic biomarkers in patients with bladder cancer) ${ }^{23}$. Molecular imaging has rapidly developed and shown great potential in early tumor diagnosis and treatment based on physical and metabolic changes ${ }^{24}$. Radioisotope-labeled target molecules for breast cancer such as ${ }^{18} \mathrm{~F}$-labeled aptamers of Her2/ErbB2 (human epidermal growth factor receptor $2)^{25}, \quad{ }^{125} \mathrm{I} /{ }^{131}$ I-labeled anti ICAM-1(intercellular cell adhesion molecule-1) antibody ${ }^{26}$ and ${ }^{89} \mathrm{Zr}$-Transferrin ${ }^{27}$, have been developed. However, these target molecules are limited by low selection and tumor expression. We developed a ${ }^{131}$ I-labeled anti-TLR5 antibody that can indicate allorejection ${ }^{28}$. Here, we aimed to determine whether this radiolabeled antibody could serve as a noninvasive monitoring target for early TNBC using the TNBC cell line, 4T1.

\section{Materials and methods Mice and reagents}

All animal studies proceeded in accordance with protocols approved by the Animal Care and Use Committee of Shandong University. Six-week-old male athymic nude mice $(20-22 \mathrm{~g})$ were purchased from Charles River Laboratories (Wilmington, MA, USA). The Lentivirus-
shRNA $\left(5^{\prime}-3^{\prime}\right.$ GCTTCAACTATATCAGTATGG) for TLR5 knockdown and negative-control virus was purchased from GenePharma (Shanghai, China). Antivimentin (\#5741), anti-N-cadherin (\#13116), anti-Ecadherin (\#3195), anti-SOX2 (\#14962) and anti-GAPDH (\#5174) antibodies were purchased from Cell Signaling Technologies (CST; Boston, MA, USA). Anti-TLR5 (\#ab168382), anti-fibronectin (\#ab45688), anti-TRAF6 (\#ab33915) and anti-Twist1 (\#ab49254) antibodies were purchased from Abcam (Cambridge, UK).

\section{Generation of TLR5 knockdown 4T1 cells}

Murine TNBC cell lines $4 \mathrm{~T}^{23}$ were obtained from the American Type Culture Collection (ATCC). The cells were seeded in 24-well plates $\left(1 \times 10^{5} /\right.$ well $)$ and incubated at $37^{\circ} \mathrm{C}$ in a humidified $5 \% \mathrm{CO}_{2}$ atmosphere overnight. The medium was then replaced with negative control virus or Lentivirus-shRNA TLR5 diluted in fresh medium at a ratio of $1: 100$, and the cells were incubated at $37^{\circ} \mathrm{C}$ in a humidified $5 \% \mathrm{CO}_{2}$ atmosphere for $24 \mathrm{~h}$. Finally, the diluted virus was replaced with fresh medium and incubation proceeded under the same conditions for another $48 \mathrm{~h}$. Thereafter, transfection efficiency was calculated. Transfected cells were filtered out using Puromycin (Beijing Solarbio Science \& Technology Co., Ltd., Beijing, China).

\section{Western blot and quantitative PCR (qPCR)}

Total protein concentrations for western blot were measured using protein assay kits (Beyotime Biotechnology, Shanghai, China). Total protein $(20 \mu \mathrm{g})$ was loaded onto gel (Bio-Rad Laboratories, Hercules, CA, USA), along with Chameleon Duo ladder protein marker (SMOBIO, Taiwan, R.O.C). Proteins were resolved by electrophoresis at $80 \mathrm{~V}$ for $30 \mathrm{~min}$ followed by $100 \mathrm{~V}$ for $60 \mathrm{~min}$ and transferred onto nitrocellulose membranes. Nonspecific binding was blocked with $5 \%$ skim milk in blocking buffer for $2 \mathrm{~h}$ at room temperature $\left(20^{\circ} \mathrm{C}\right)$ and further incubated overnight at $4^{\circ} \mathrm{C}$ with 1:1000 diluted rabbit anti-mouse TLR5/vimentin/fibronectin/N-cadherin/E-cadherin/TRAF6/SOX2/Twist1 antibodies and 1:10000 diluted rabbit anti-mouse GAPDH antibody. Membranes were washed three times with TBS-Tween 20 (TBS-T), incubated with anti-rabbit IgG antibodies (1:5000) for $2 \mathrm{~h}$ at room temperature, then scanned and quantified using a Tanon 4200 imaging system (Tanon Science and Technology Co., Ltd., Shanghai, China).

Total RNA was extracted for qPCR from 4T1 cells using the TRIzol reagent (Invitrogen) according to the manufacturer's instructions. After determining the RNA concentration, the cDNA first strand was synthesized via TransScript First-Strand cDNA Synthesis SuperMix (TRANSGEN BIOTECH, Beijing, China). The mRNA was then measured using TransStart Tip Green qPCR 
SuperMix (TRANSGEN BIOTECH, Beijing, China) with the following forward and reverse primers, respectively:

TLR5, 5' -GCAGGATCATGGCATGTCAAC-3' and 5'ATCTGGGTGAGGTTACAGCCT-3';

E-cadherin, 5' -CAGGTCTCCTCATGGCTTTGC-3' and 5'-CTTCCGAAAAGAAGGCTGTCC-3';

N-cadherin, 5' - AGCGCAGTCTTACCGAAGG-3' and

5'-TCGCTGCTTTCATACTGAACTTT-3';

vimentin, 5' - CGTCCACACGCACCTACAG3' and 5'-

GGGGGATGAGGAATAGAGGCT-3';

TRAF6, 5' - TAAGGGATGCAGGGCACAAG-3' and 5'- GGCACTTTACCGTCAGGGAA-3';

SOX2, 5' - TTTGTCCGAGACCGAGAAGC-3' and $5^{\prime}$ CTCCGGGAAGCGTGTACTTA-3';

Twist1, 5'- GGACAAGCTGAGCAAGATTCA-3' and 5'-CGGAGAAGGCGTAGCTGAG-3'.

\section{CCK-8 assays}

Cell proliferation was evaluated using CCK-8 assays. $\mathrm{TLR}^{+}$and TLR5 ${ }^{-} 4 \mathrm{~T} 1$ cells $\left(2 \times 10^{3}\right.$ well $)$ were, respectively, seeded in 96-well plates overnight, and the absorbance was measured at $450 \mathrm{~nm}$ after $0,6,24,36$, and $48 \mathrm{~h}$ by using a microplate reader. Experiments were repeated three times.

\section{Flow cytometry}

Apoptosis was evaluated by digesting TLR $5^{+}$and TLR $5^{-}$ 4T1 cells with $0.25 \%$ trypsin (without EDTA and phenol red), after which, the cells were sedimented by centrifugation (speed in $800 g$, for $5 \mathrm{~min}$ ). The cells were washed twice with cold PBS and suspended in $400 \mu \mathrm{L}$ of $1 \times$ annexin $\mathrm{V}$ binding solution at a concentration of $1 \times$ $10^{6} / \mathrm{mL}$. Annexin V-YF647A $(5 \mu \mathrm{L})$ was gently mixed with $10 \mu \mathrm{L}$ of PI staining solution, incubated at $4{ }^{\circ} \mathrm{C}$ for $15 \mathrm{~min}$ in darkness, passed through a 200-mesh filter, and immediately analyzed by flow cytometry. Experiments were repeated three times.

\section{Colony formation}

$\mathrm{TLR}^{+}$and TLR5 ${ }^{-} 4 \mathrm{~T} 1$ cells $\left(1 \times 10^{3} /\right.$ well $)$ were seeded in six-well plates and the medium was changed every 3-4 days. The plates were incubated at $37^{\circ} \mathrm{C}$ in a humidified incubator for 14 days. At the end of the experiment, the cells were washed with PBS, incubated with $0.005 \%$ crystal violet for $15 \mathrm{~min}$, then rinsed with PBS. Colony formation rates were calculated as follows: (number of colonies/number of seeded cells) $\times 100 \%$. Experiments were repeated three times.

\section{Wounding healing assays}

$\mathrm{TLR}^{+}$and TLR5 ${ }^{-}$4T1 cells were seeded in six-well plates and incubated overnight to obtain confluent monolayers. Monolayers were scratched using a sterile pipette tip, and wounds were examined after incubation at $37^{\circ} \mathrm{C}$ in a humidified $5 \% \mathrm{CO}_{2}$ incubator for $24 \mathrm{~h}$. Experiments were repeated three times.

\section{Transwell assays}

These assays proceeded in 24-well Transwell units with an $8 \mu \mathrm{m}$ pore polycarbonate membrane. Matrigel $(100 \mu \mathrm{L}$; $300 \mu \mathrm{g} / \mathrm{mL}$ ) was added to the upper compartment. After overnight starvation, suspended cells were seeded in the upper compartment in serum-free medium, and medium supplemented with $10 \%$ FBS as a chemoattractant was placed in the lower compartment. Cells in the upper compartment were removed $24 \mathrm{~h}$ later by gentle swabbing. Cells that had migrated to the lower surface of the membrane were stained with crystal violet and counted at $400 x$ magnification in five high power fields. Triplicate samples were tested, and the experiment was repeated three times.

\section{Lung metastasis experiment}

Mice were injected with $1 \times 10^{6} \mathrm{TLR}^{+}$or TLR5 ${ }^{-}$ $4 \mathrm{~T} 1$ cells via the tail vein, and the mouse lungs were weighed 20 days later and dissected for hematoxylin and eosin (H\&E) staining and fluorescence imaging. The experiment was repeated at least three times.

\section{T1 breast cancer-bearing mice model}

All animal studies proceeded in accordance with protocols approved by the Animal Care and Use Committee of Shandong University. Subcutaneous $\mathrm{TLR}^{+}$and TLR5 ${ }^{-}$4T1 tumor cells were induced in 6-week-old nude male mice, respectively, by injecting their lower left and right flanks with $1 \times 10^{6} \mathrm{TLR}^{+} 4 \mathrm{~T} 1$ and TLR5 ${ }^{-} 4 \mathrm{~T} 1$ cells suspended in $200 \mu \mathrm{L}$ of PBS. The tumors on mice were monitored every other day. The tumor-bearing mice were assessed by phosphor-autoradiography and fluorescence imaging, and biodistribution was also determined.

\section{Preparation of ${ }^{125} \mathrm{I}$-anti-TLR5 mAb and ${ }^{125} \mathrm{I}$-lgG}

We prepared ${ }^{125} \mathrm{I}$-anti-TLR5 and ${ }^{125} \mathrm{I}$-IgG as described previously $^{28}$. A 1:2 (v/v) mixture of $0.9 \%$ saline and methanol served as an unfolding agent. The stability of ${ }^{125} \mathrm{I}$-anti-TLR5 $\mathrm{mAb}$ and ${ }^{125} \mathrm{I}$-IgG in PBS was evaluated using paper chromatography in PBS and murine serum, then radioactivity was determined using a Gamma counter. Competitive binding was assessed in TLR5 ${ }^{+}$ $4 \mathrm{~T} 1$ cells $\left(5 \times 10^{5} /\right.$ well $)$ seeded in 24 -well plates with $0.1-1000 \mathrm{nM}$ anti-TLR5 $\mathrm{mAb}$ and $10 \mathrm{nM}{ }^{125} \mathrm{I}$-anti-TLR5 $\mathrm{mAb}$ and incubated at $37^{\circ} \mathrm{C}$ for $45 \mathrm{~min}$. The supernatants were discarded, and then the cells were washed twice with iced $1 \times$ PBS containing $0.1 \%$ BSA and harvested for radioactivity determination using a Gamma counter.

\section{Dynamic whole-body phosphor-autoradiography}

Three days before radiotracers injection, $3 \%$ potassium iodide was added to the drinking water of the mice to 
block iodine uptake by the thyroid gland. Tumor-bearing mice (total $n=50, n=25$ per group, randomly divided) were each injected with $0.37 \mathrm{MBq}$ of ${ }^{125} \mathrm{I}$-antiTLR5 $\mathrm{mAb}$ $(0.38 \mu \mathrm{g})$ or ${ }^{125} \mathrm{I}-\mathrm{IgG}(0.38 \mu \mathrm{g})$ via the tail vein. Wholebody phosphor-autoradiography scanning proceeded on day $6,8,10,12$, and 14 after tumor cell inoculation (at $48 \mathrm{~h}$ after the ${ }^{125} \mathrm{I}$-antiTLR5 or ${ }^{125} \mathrm{I}$-IgG injections), respectively. For the blocking group $(n=5$, randomly divided), mice were injected with unlabeled anti-TLR5 $\mathrm{mAb}(100 \mu \mathrm{g}) 30 \mathrm{~min}$ before the ${ }^{125} \mathrm{I}$-antiTLR5 $\mathrm{mAb}$ $(0.37 \mathrm{MBq}, 0.38 \mu \mathrm{g})$ injection. Whole-body phosphorautoradiography scanning proceeded on day 12 after tumor cell inoculation (at $48 \mathrm{~h}$ after the ${ }^{125} \mathrm{I}$-antiTLR5 injections). Mice anesthetized with sodium pentobarbital $(0.6 \%)$ were placed supine on a storage phosphor screen plate (back to the plate) and left for $20 \mathrm{~min}$ in darkness. Plate was then transferred to a Cyclone Plus scanner (PerkinElmer). Manually drawn rectangular regions of interest $(n=5)$ within the target area at each time point were semi-quantified. Digital light units (DLU) $/ \mathrm{mm}^{2}$ were obtained using OptiQuant ${ }^{\mathrm{TM}}$ image analysis software 5.0 (PerkinElmer). Tumors were individually stripped and imaged.

\section{Fluorescence imaging}

The $4 \mathrm{~T} 1$ cells were transfected with lentivirus-TLR5 knockdown, and the lentivirus expressed green fluorescent protein (GFP) after integration into 4T1 cells. Subcutaneous TLR $^{-}$and TLR $^{+}$4T1 tumors were induced as described above with TLR $5^{-} 4 \mathrm{~T} 1$ and TLR $5^{+}$ 4T1 cells injected into the lower right and left flanks, respectively, and $4 \mathrm{~T} 1$ cells without Lentivirus transfection were injected into the back. The mice were anesthetized on day $6,8,10,12$, and 14 after tumor cell inoculation, respectively, then the skin on the surface of the tumors was peeled, and the mice were placed prone on the imaging plate and photographed using IVIS Spectrum (PerkinElmer).

\section{Biodistribution studies}

Three days before injecting the radiotracers, 3\% potassium iodide was added to the drinking water of the mice to block iodine uptake by the thyroid gland. Model mice (total $n=30, n=15$ per group, randomly divided) were injected with ${ }^{125} \mathrm{I}$-anti-TLR5 $\mathrm{mAb}$ or ${ }^{125} \mathrm{I}$-IgG (0.37 MBq), then sacrificed, and dissected 24, 48, and $72 \mathrm{~h}$ later. Tumors, blood, and major tissues/organs (heart, lung, liver, kidney, spleen, small intestine, and muscle) were harvested and weighed. Samples and primed standards were measured using a Gamma counter. Tissue radioactivity was expressed as the percent injected dose per gram (\%ID/g), and the target to non-target (T/NT) ratio was defined as the ratio of radioactivity that accumulated in tumors to that in the contralateral muscle. The experiment was repeated three times.

\section{H\&E and immunohistochemical staining}

Tumor-bearing mice $(n=5)$ were sacrificed $72 \mathrm{~h}$ after completing whole-body phosphor-autoradiography. Tumors were isolated for immunohistochemical staining with rabbit polyclonal TLR5 antibody (Beijing Biosynthesis Biotechnology Co., Ltd., Beijing, China) and DAB chromogen (Biogenics Inc., Napa, CA, USA). Immunohistochemistry proceeded using SP-9002 Histostain $^{\text {TM }}$ Plus kits (ZSGB-BIO, Beijing, China) according to the manufacturer's protocols. Sections on slides were visualized at 200x and 400x magnification. Corresponding positive areas of sections were analyzed (five fields per slide) using Image-Pro Plus software version 4.5.0.29 (Media Cybernetics Inc., Rockville, MD, USA). The experiment was repeated five times.

\section{Statistical analysis}

Data were presented as the means \pm standard deviation (SD) derived from at least three independent experiments. Student $t$ tests were applied using Graph Pad Prism version 5 (GraphPad Software Inc., La Jolla, CA, USA). Significant differences were considered at ${ }^{*} P<0.05$ and ${ }^{* * *} P<$ 0.01 .

\section{Results}

TLR5 downregulation prompted epithelial-mesenchymal transition (EMT) in $4 \mathrm{~T} 1$ cells

We quantified the protein and mRNA expression of TLR5, E-cadherin, N-cadherin, vimentin, fibronectin, TRAF6, SOX2 and the transcription factor, Twist1, by western blot and qPCR to verify the effects of TLR5 on EMT (Fig. 1a and b, respectively). The protein expression of E-cadherin significantly decreased after TLR5 downregulation, whereas those of vimentin, fibronectin, N-cadherin, TRAF6, SOX2 and Twist1 increased. The trend in mRNA levels was similar. These results suggested that TLR5 downregulation induced EMT increasing via TRAF6 and SOX2 pathway in TNBC.

\section{TLR5 downregulation prompted 4T1 tumor cell proliferation, colony formation, and migration in vitro}

We initially determined the survival of patients with breast cancer according to TLR5 gene data using Kaplan-Meier plotter (http://kmplot.com/analysis/) and found significantly worse survival rates among patients with low TLR5 expression in tumors(Fig. 2a). Thereafter, CCK- 8 assays showed that the ability to proliferate was higher for TLR $5^{-} 4 \mathrm{~T} 1$ than for TLR $5^{+} 4 \mathrm{~T} 1$ cells. The OD $(450 \mathrm{~nm})$ of TLR $5^{+} 4 \mathrm{~T} 1$ vs. TLR5 ${ }^{-} 4 \mathrm{~T} 1$ cells at $6,12,24$, 36 , and 48 h were $0.27 \pm 0.01$ vs. $0.26 \pm 0.03,0.28 \pm 0.01$ vs. $0.35 \pm 0.02,0.78 \pm 0.04$ vs. $1.01 \pm 0.09,1.19 \pm 0.06$ vs. 

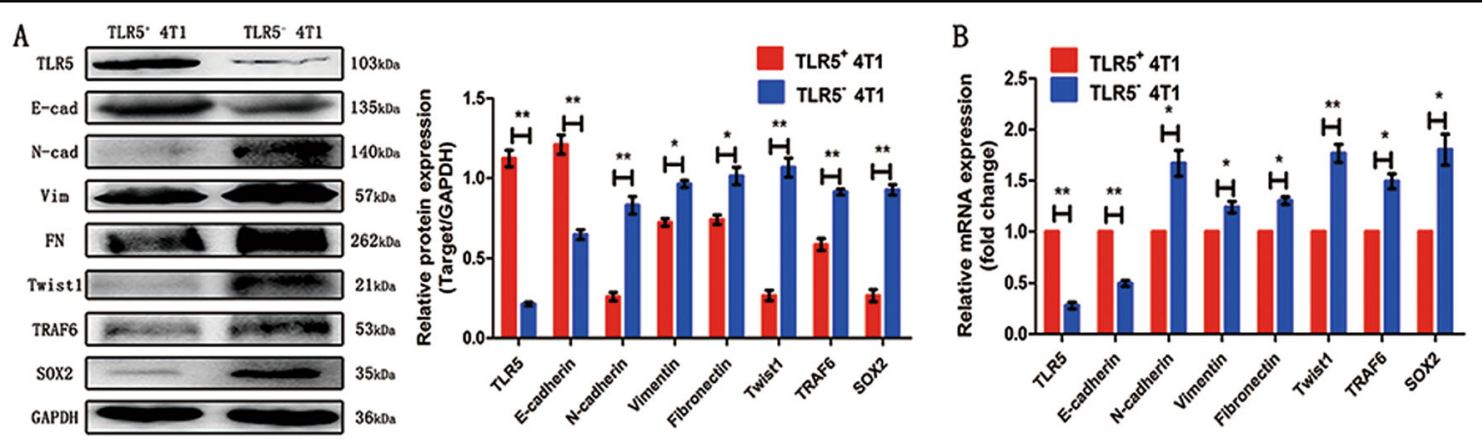

Fig. 1 TLR5 downregulation promoted EMT in $\mathbf{4 T 1}$ cells. TLR5, E-cadherin, N-cadherin, vimentin, fibronectin,TRAF6, SOX2 and Twist1 protein expression of TLR5 ${ }^{+} 4 \mathrm{~T} 1$ and TLR5 ${ }^{-} 4 \mathrm{~T} 1$ cells was detected by western Blot $\left(n=3,{ }^{*} P<0.05\right)(\mathbf{a})$. TLR5, E-cadherin, N-cadherin, vimentin, fibronectin, TRAF6, SOX2 and Twist1 mRNA expression of TLR5 ${ }^{+} 4 \mathrm{~T} 1$ and TLR5 ${ }^{-} 4 \mathrm{~T} 1$ cells was detected by qPCR $\left(n=3,{ }^{*} P<0.05\right)$ (b). Representative results of three independent experiments were reported. The data were presented as the means \pm SD from three independent experiments, analyzed by Student's $t$ test. ${ }^{*} P<0.05,{ }^{* *} P<0.01$.

$1.60 \pm 0.05$, and $1.78 \pm 0.08$ vs. $2.26 \pm 0.07$, respectively (Fig. 2b). Apoptosis in TLR5-downregulated 4T1 cells did not significantly change compared with the negative control (Fig. 2c, $P>0.05$ ). We evaluated the ability of $4 \mathrm{~T} 1$ cells to form tumors using colony formation assays to further determine the effects of TLR5 on tumor cell proliferation. Figure $2 \mathrm{~d}$ shows that significantly more colonies were formed by $\mathrm{TLR} 5^{-} 4 \mathrm{~T} 1$ than by $\mathrm{TLR} 5^{+}$ $4 \mathrm{~T} 1$ cells, indicating higher tumorigenicity. The colony formation rates of TLR $5^{-} 4 \mathrm{~T} 1$ vs. TLR5 $5^{+} 4 \mathrm{~T} 1$ were $76 \pm$ $8 \%$ vs. $59 \pm 4 \%(P<0.05)$, respectively. We verified differences in migration and invasiveness between TLR $5^{+}$ 4T1 and TLR5 ${ }^{-}$4T1 cells using wound healing and transwell assays. The migration area was larger in the $\mathrm{TLR}^{-}$4T1, than the TLR5 ${ }^{+}$4T1 group, and the migration area ratio of $\mathrm{TLR}^{+}$vs. TLR $5^{-} 4 \mathrm{~T} 1$ cells was $71.67 \pm$ $3.05 \%$ vs. $55.33 \pm 3.51 \%(P<0.01$; Fig. 2 e). Transwell invasion assays showed that the number of migrated cells was remarkably lower in the TLR $5^{+} 4 \mathrm{~T} 1$ group than in the TLR5 ${ }^{-}$4T1 group ( $35 \pm 5$ vs. $82 \pm 15$ cells/area; $P<$ 0.01; Fig. 2f).

\section{TLR5 downregulation promoted 4T1 metastasis in vivo}

At 21 days after injecting TLR $5^{+} 4 \mathrm{~T} 1$, TLR $^{-} 4 \mathrm{~T} 1$ and non-transfected $4 \mathrm{~T} 1$ cells via the tail vein, the lungs were stripped from the mice, weighed, and assessed by fluorescence imaging and histological analysis. Figure 3a shows much larger green fluorescence areas indicating metastatic sites in the TLR5 ${ }^{-}$4T1 than in the TLR5 ${ }^{+} 4 \mathrm{~T} 1$ group, and green fluorescence was absent in the nontransfected 4T1 group. The lungs were the heaviest, averaging $\sim 280 \mathrm{mg}$ and reaching $300 \mathrm{mg}$, in the TLR5 ${ }^{-}$ 4T1groups, whereas normal lungs weighed approximately $120 \mathrm{mg}$ (Fig. 3b). Differences were quite apparent among the three groups $(P<0.05)$. Staining with $H \& E$ revealed typical tumor tissues changes within the lungs where fluorescence imaging positively. Tumor cells that metastasized to the lungs were closely arranged and had larger nuclei than those in normal lung tissues. The number and size of metastases were significantly smaller in the TLR5 ${ }^{+} 4 \mathrm{~T} 1$ than in the TLR5 ${ }^{-}$4T1 group (Fig. 3c).

\section{Successful preparation of ${ }^{125}$ I-anti-TLR5 mAb and ${ }^{125} \mathrm{I}$-lgG}

The radiochemical purity of ${ }^{125} \mathrm{I}$-antiTLR $5 \mathrm{mAb}$ and ${ }^{125} \mathrm{I}$-IgG was both $>90 \%$. Both tracers were stable at $>95 \%$ up to $72 \mathrm{~h}$ and relatively stable in serum and normal saline with no detectable significant differences between them (Fig. 4a and B). Competitive binding analysis using $>500$ fold excess of unlabeled anti-TLR5 mAb almost completely blocked ${ }^{125} \mathrm{I}$-anti-TLR $5 \mathrm{mAb}(<5 \%)$ binding, with nonspecific binding for ${ }^{125}$ I-IgG being $\sim 2 \%$ (Fig. 4c).

\section{Dynamic phosphor-autoradiography and fluorescence imaging in vivo}

Dynamic phosphor-autoradiography and fluorescence imaging proceeded on day $6,8,10,12$, and 14 after the mice were subcutaneously injected with TLR5 ${ }^{+} 4 \mathrm{~T} 1$ and $\mathrm{TLR}^{-}$4T1 cells and at $48 \mathrm{~h}$ after injecting them with ${ }^{125}$ I-anti-TLR5 mAb (Fig. 5a). Whole-body phosphorautoradiography showed higher and lower radioactivity uptake by $\mathrm{TLR}^{+} 4 \mathrm{~T} 1$ and TLR5 $5^{-} 4 \mathrm{~T} 1$ tumors, respectively, at all time points. Dynamic phosphorautoradiography on day 6 clearly showed TLR $5^{+} 4 \mathrm{~T} 1$ tumors, whereas TLR5 $^{-}$4T1 tumors were unclear. However, fluorescence imaging on day 6 clearly showed the location and boundary of TLR $5^{-} 4 \mathrm{~T} 1$ tumors, which might be due to the high specificity of ${ }^{125} \mathrm{I}$-anti-TLR5 $\mathrm{mAb}$ binding. The radioactivity (DLU) $/ \mathrm{mm}^{2}$ was 6.67 -fold higher in $\mathrm{TLR}^{+}$4T1 than in TLR5 ${ }^{-} 4 \mathrm{~T} 1$ tumors $(141,525 \pm 8554$ vs. $21,254 \pm 2257 \mathrm{cpm})$. Autoradiography and fluorescence double imaging confirmed that TLR5 was a good reporter for noninvasive monitor and predictor of TNBC. Tumors were not obvious in specifically blocked and ${ }^{125}$ I-IgG groups at any checked time point, 


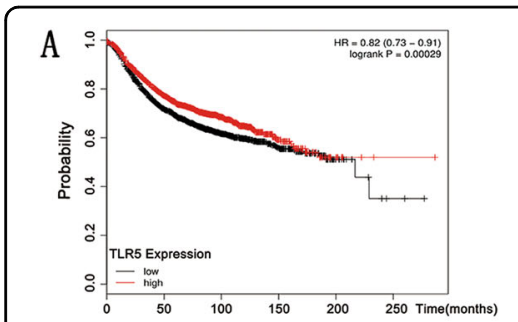

Prognostic information of TLR5

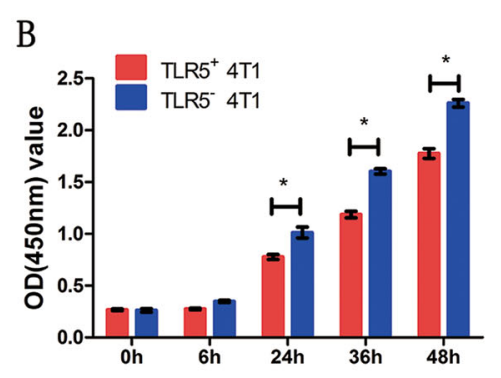

D

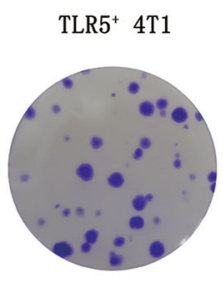

TLR5- 4 T1

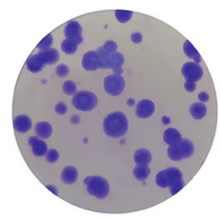

E TLR5 ${ }^{-}$4T1

oh
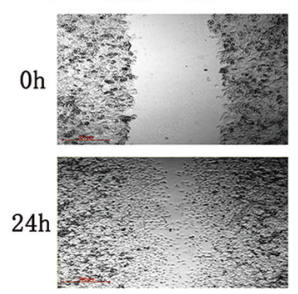

C

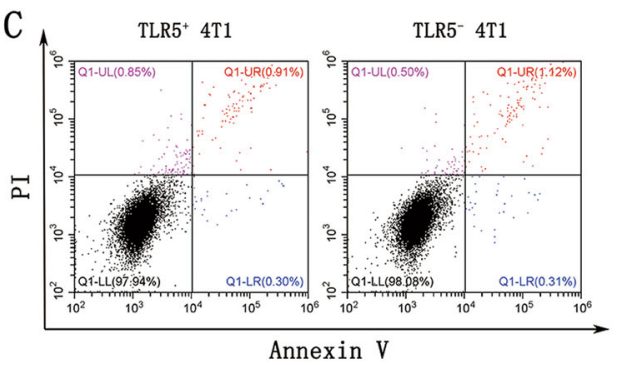

$\mathrm{F}$
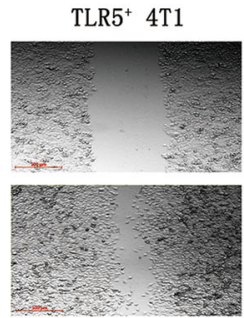

TLR5 ${ }^{+}$4T1

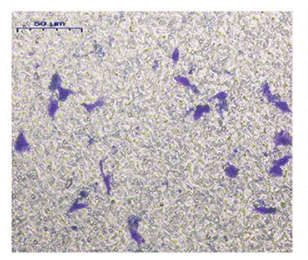

TLR5- 4 T1

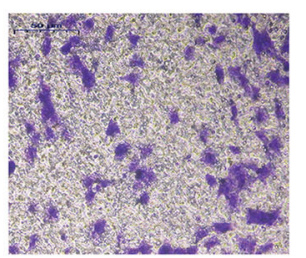

Fig. 2 TLR5 downregulation enhanced 4T1 tumor cell proliferation, migration and invasiveness in vitro. Kaplan-Meier plotter online tools were used to identify that the patients suffered from breast cancer with low TLR5 expression had a significantly worse survival rate (a). CCK-8 assay showed that TLR5 ${ }^{-} 4 \mathrm{~T} 1$ cells have higher proliferation ability than $\mathrm{TLR}^{+} 4 \mathrm{~T} 1$ cells (b).No difference in apoptosis change in TLR5 downregulated $4 \mathrm{~T} 1$ cells was detected compared with negative control group (c). The colony formation ability of TLR5 ${ }^{-} 4 \mathrm{~T} 1$ cells was significantly increased than TLR5 $^{+} 4 \mathrm{~T} 1$ cells $(\mathbf{d})$.The migration area of TLR5 ${ }^{-}$4T1 group was larger than TLR5 ${ }^{+} 4 \mathrm{~T} 1$ group (e). The number of migrated cells was remarkably reduced in $\mathrm{TLR}^{+} 4 \mathrm{~T} 1$ group than TLR5 ${ }^{-} 4 \mathrm{~T} 1$ group $(\mathbf{f})$. The data were presented as the means $\pm \mathrm{SD}(n=3)$ from three independent experiments, analyzed by Student's $t$ test. ${ }^{*} P<0.05,{ }^{*} P<0.01$.

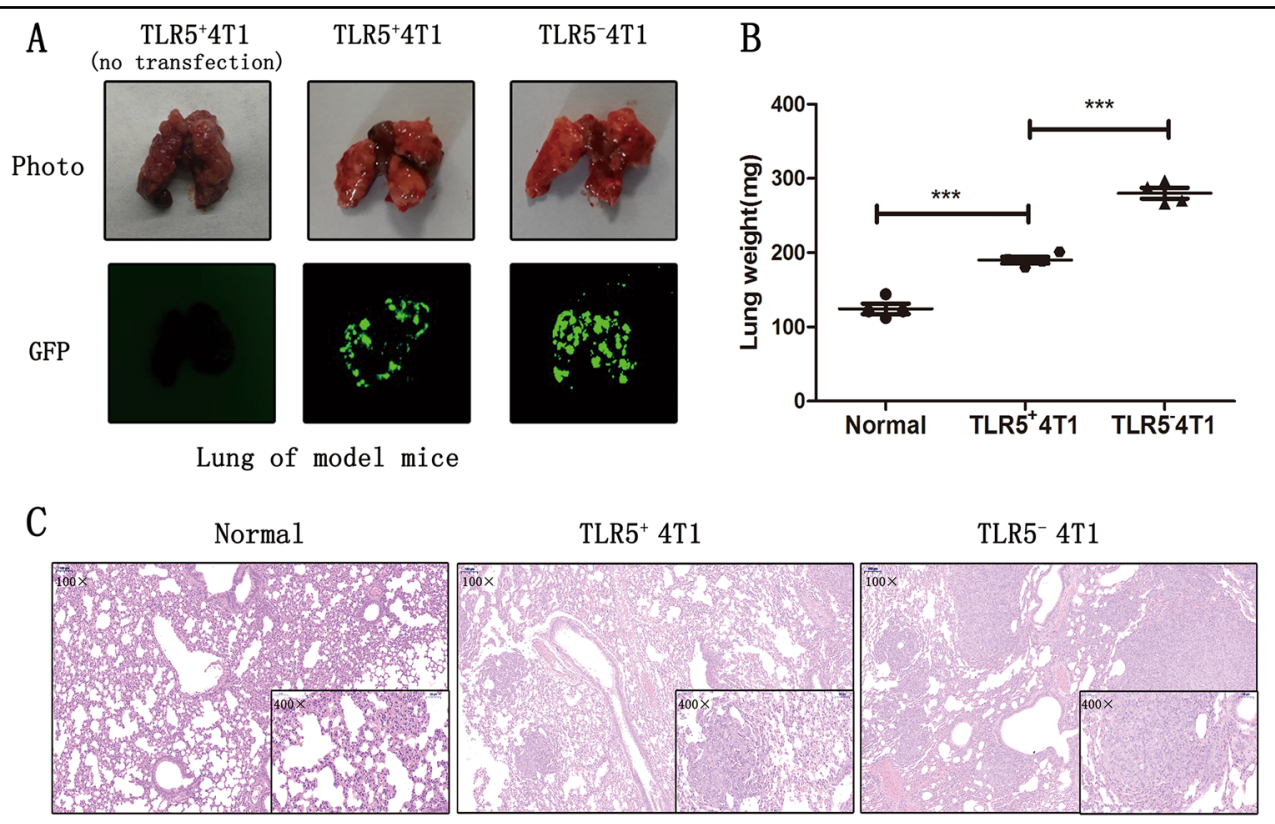

Fig. 3 TLR5 downregulation promoted lung metastasis of 4T1 in vivo. Fluorescence images of stripped lungs of mice models: naive 4T1 (no Lentivirus transfection), $\mathrm{TLR}^{+}$4T1 (with negative Lentivirus transfection) and TLR5 ${ }^{-}$4T1 (with Lentivirus-shRNA TLR5 knockdown transfection) (a). Lungs from untreated mice, TLR5 ${ }^{+} 4 \mathrm{~T} 1$ and TLR5 ${ }^{-}$4T1 model mice were weighed (b) and H\&E staining was performed $(\mathbf{c})(n=3, * * P<0.01)$. Representative results of three independent experiments were reported. The data were presented as the means \pm SD. The data were analyzed by Student's $t$ test. ${ }^{*} P<0.05,{ }^{* *} P<0.01$. 

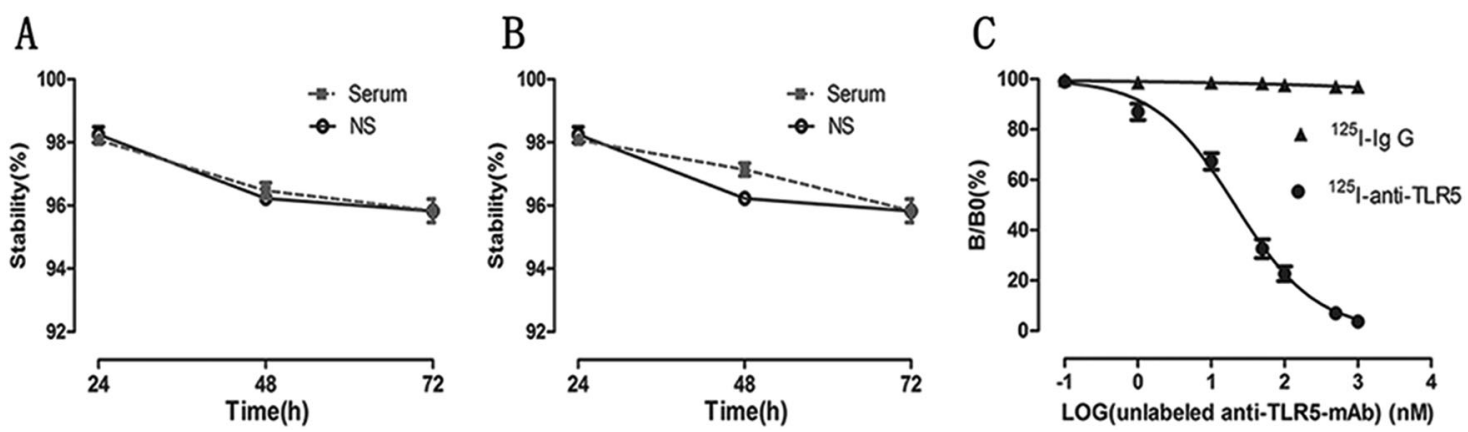

Fig. 4 Evaluation of prepared radiolabeled tracers in vitro. The stability of ${ }^{125} \mathrm{I}$-antiTLR5 mAb (a) and ${ }^{125} \mathrm{~F}-\mathrm{lgG}$ (b) in serum and normal saline changes over time. The concentration of the labeled tracer ( ${ }^{125} \mathrm{~F}$-anti-TLR5 mAb or ${ }^{125} \mathrm{I}-\mathrm{lgG}$ ) was kept constantly, and increasing concentrations of unlabeled anti-TLR5 mAb were used to compete with the ${ }^{125}$ I-anti-TLR5 mAb binding (c).
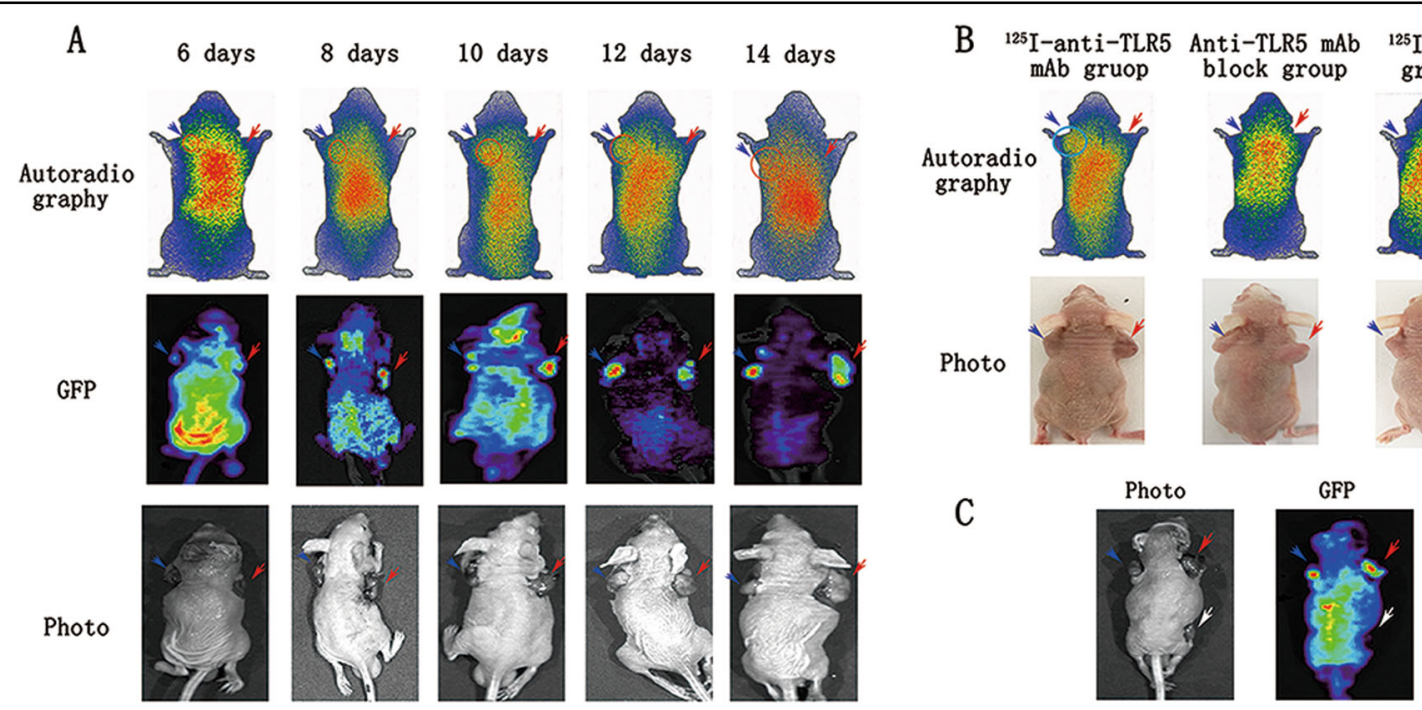

Fig. 5 Dynamic phosphor-autoradiography and Fluorescence imaging. Representative images were performed at $48 \mathrm{~h}$ post-injection of ${ }^{125}$ I-antiTLR5 $\mathrm{mAb} /{ }^{125} \mathrm{I}-\mathrm{lgG}$. The red arrow pointed to the TLR5 ${ }^{-}$tumor, and the blue was TLR5 ${ }^{+}$tumor and the white was TLR5 $^{+}$without Lentivirus transfer $(\mathbf{a}-\mathbf{c})$. From day 6 to day 14, representative images of tumor-bearing mice in phosphor-autoradiography and fluorescence imaging (a). Representative phosphor-autoradiography images for the ${ }^{125}$-antiTLR5 mAb group, block group and ${ }^{125}$ I-IgG group (b). Representative images of fluorescence imaging (c). Representative results of three independent experiments were reported.

suggesting specific ${ }^{125}$ I-anti-TLR5 mAb accumulation in TLR5-positive tumors(Fig. 5b). Furthermore, to confirm that tumor fluorescence was GFP-tagged, transfected, virus-derived, and TLR5-specific, we inoculated mice with three types of tumors cells. The 4T1 tumors on the right and left flanks were transfected with lentivirus-TLR5 knockdown and negative-control Lentivirus, respectively, and the 4T1 tumor on the back was not transfected. Figure $5 \mathrm{c}$ clearly showed tumors in both flanks, whereas the non-transfected 4T1 tumor appeared black.

\section{Tumor imaging ex vivo}

Radioactivity accumulation was higher in isolated $\mathrm{TLR}^{+}$4T1 than in $\mathrm{TLR}^{-}$4T1 tumors visualized by imaging ex vivo (Fig. 6a). Furthermore, the weight and volume were much larger for TLR $5^{-} 4 \mathrm{~T} 1$ than for TLR $5^{+}$ $4 \mathrm{~T} 1$ tumors (Fig. 6b, c; $P<0.05$ ).

\section{Biodistribution studies}

To validate the imaging results and further quantify ${ }^{125}$ I-antiTLR5 mAb uptake at 24,48 , and $72 \mathrm{~h}$, biodistribution studies in vitro proceeded 14 days after TLR $5^{+}$ $4 \mathrm{~T} 1$ and TLR5 ${ }^{-}$4T1 tumor cell inoculation. Table 1 showed that the T/NT (target to non-target) ratio was the highest in TLR5 ${ }^{+} 4 \mathrm{~T} 1$ tumors at $48 \mathrm{~h}$. Targeting by the ${ }^{125} \mathrm{I}$-antiTLR $5 \mathrm{mAb}$ was more efficient in $\mathrm{TLR}^{+}{ }^{+}$4T1 than in TLR5 $5^{-}$4T1 tumors. The uptake of ${ }^{125} \mathrm{I}$-antiTLR5 $\mathrm{mAb}$ in $\mathrm{TLR}^{+} 4 \mathrm{~T} 1$ tumors at 24,48 , and $72 \mathrm{~h}$ post- 


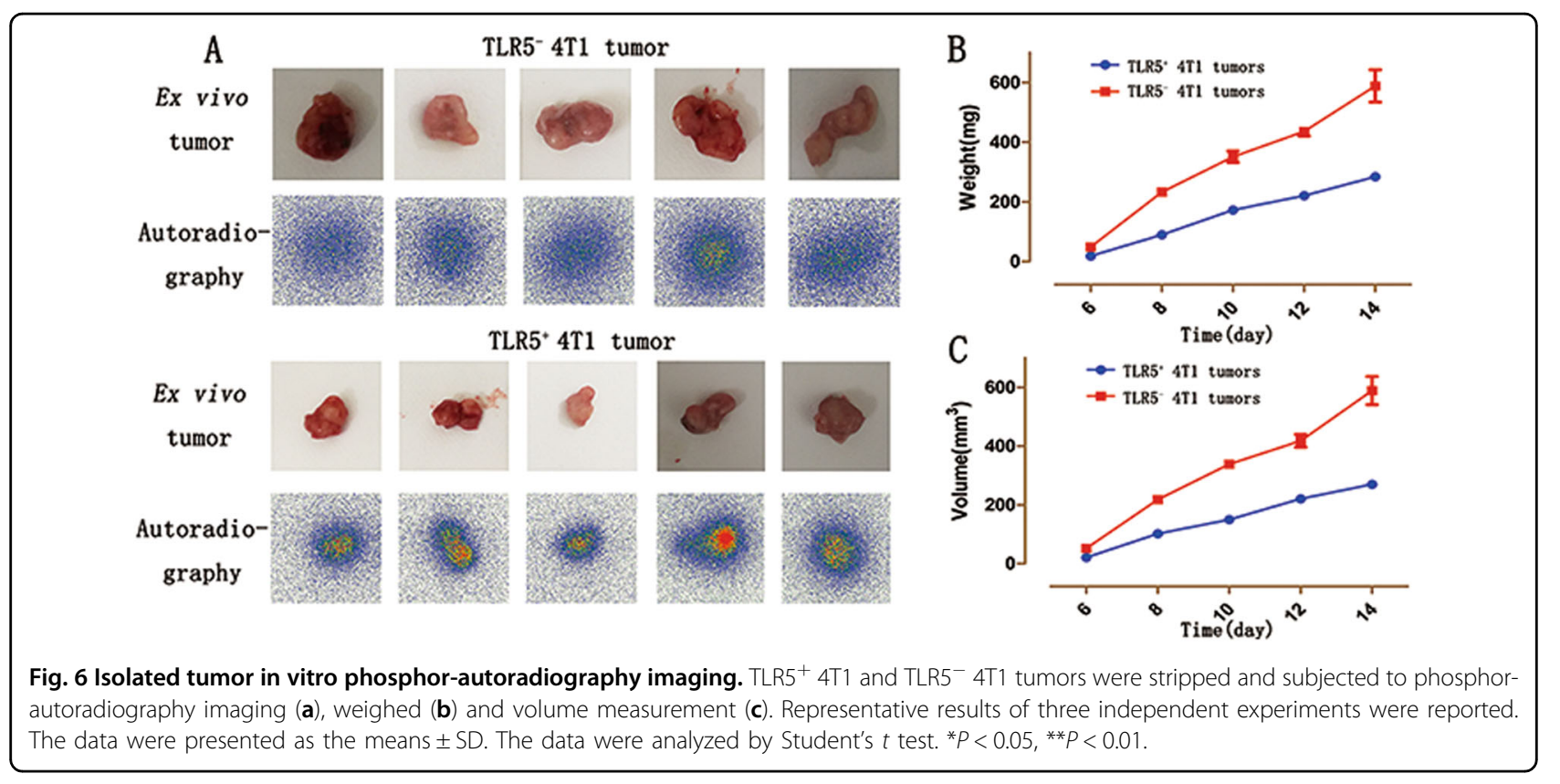

Table 1 Biodistribution of ${ }^{125}$ I-anti-TLR5 $\mathrm{mAb}$ in TLR5 $^{+}$ and TLR5 $^{-}$4T1 tumor models group.

\begin{tabular}{|c|c|c|c|}
\hline & \multicolumn{3}{|l|}{ Time (h) } \\
\hline & 24 & 48 & 72 \\
\hline Blood & $4.47 \pm 0.55$ & $2.87 \pm 0.41$ & $1.42 \pm 0.12$ \\
\hline Thyroid & $2.28 \pm 0.13$ & $1.15 \pm 0.31$ & $1.46 \pm 0.40$ \\
\hline Heart & $2.02 \pm 0.32$ & $1.63 \pm 0.09$ & $1.15 \pm 0.12$ \\
\hline Lung & $5.00 \pm 0.87$ & $1.31 \pm 0.31$ & $1.23 \pm 0.14$ \\
\hline Liver & $7.56 \pm 0.71$ & $2.91 \pm 0.23$ & $2.05 \pm 0.12$ \\
\hline Spleen & $4.05 \pm 0.99$ & $0.86 \pm 0.07$ & $0.66 \pm 0.11$ \\
\hline Kidney & $8.36 \pm 1.02$ & $3.02 \pm 0.77$ & $1.38 \pm 0.20$ \\
\hline Intestines & $1.41 \pm 0.20$ & $0.54 \pm 0.22$ & $0.59 \pm 0.37$ \\
\hline Bone & $0.85 \pm 0.26$ & $0.61 \pm 0.15$ & $0.29 \pm 0.05$ \\
\hline Muscle & $1.20 \pm 0.14$ & $0.59 \pm 0.11$ & $0.37 \pm 0.06$ \\
\hline Tumor(TLR5 ${ }^{+}$) & $7.73 \pm 0.75^{* *}$ & $4.92 \pm 0.36^{* *}$ & $2.58 \pm 0.18^{* *}$ \\
\hline Tumor(TLR5-) & $1.39 \pm 0.10$ & $0.70 \pm 0.05$ & $0.42 \pm 0.03$ \\
\hline
\end{tabular}

$125 /$ radiolabeled sodium iodide, $h$ hours

${ }^{*} P<0.01$ compared to the TLR5 ${ }^{+} 4 \mathrm{~T} 1$ tumor and the TLR5 ${ }^{-} 4 \mathrm{~T} 1$ tumor in the same mouse. Data are presented as a mean percent injected dose per gram $(\% \mathrm{ID} / \mathrm{g}) \pm$ standard deviation (Mean $\pm \mathrm{SD}$ ) of five animals

injection were $7.73 \pm 0.75,4.92 \pm 0.36$, and $2.58 \pm 0.18$ (\%ID/g), respectively, with $\mathrm{T} / \mathrm{NT}$ ratios of $6.84 \pm 1.04$, $8.41 \pm 0.91$, and $7.15 \pm 1.8$, respectively, whereas ${ }^{125} \mathrm{I}$ antiTLR5 $\mathrm{mAb}$ uptake in TLR5 ${ }^{-}$4T1 tumors was $1.39 \pm 0.1,0.7 \pm 0.05$, and $0.42 \pm 0.03(\% \mathrm{ID} / \mathrm{g})$, respectively, with $\mathrm{T} / \mathrm{NT}$ ratios of $1.16 \pm 0.06,1.21 \pm 0.15$, and $1.15 \pm$ 0.13 , respectively. The $\mathrm{T} / \mathrm{NT}$ ratio of the ${ }^{125} \mathrm{I}$-antiTLR5
mAb was significantly lower for TLR $5^{-} 4 \mathrm{~T} 1$ than for $\mathrm{TLR}^{+} 4 \mathrm{~T} 1$ tumors. In addition, that of ${ }^{125} \mathrm{I}$-IgG was only $1.48 \pm 0.23$ at $48 \mathrm{~h}$, suggesting nonspecific ${ }^{125} \mathrm{I}$-IgG tumor binding. In the block group, the ${ }^{125} \mathrm{I}$-anti-TLR5 $\mathrm{mAb}$ uptake of TLR5 ${ }^{+} 4 \mathrm{~T} 1$ tumor was only $1.67 \pm 0.14 \% \mathrm{ID} / \mathrm{g}$ at $48 \mathrm{~h}$, suggesting that ${ }^{125} \mathrm{I}$-antiTLR5 binding with tumor was blocked by unlabeled anti-TLR $5 \mathrm{mAb}$ pre-injection in vivo. At $48 \mathrm{~h}$, the $\mathrm{T} / \mathrm{L}$ (tumor to liver), $\mathrm{T} / \mathrm{K}$ (tumor to kidney), and $\mathrm{T} / \mathrm{B}$ (tumor to blood) ratios were significantly higher for the TLR5 ${ }^{+} 4 \mathrm{~T} 1$ tumor than for the TLR5 ${ }^{-}$4T1 tumor $(1.70 \pm 0.18$ vs. $0.24 \pm 0.02,1.68 \pm 0.28$ vs. $0.24 \pm 0.04$, and $1.73 \pm 0.12$ vs. $0.25 \pm 0.02$, respectively; $P<0.01$ for all). Background radioactivity in all other organs and tissues was minimal, which was in agreement with the imaging data.

\section{H\&E and immunohistochemical staining}

Figure 7a, c show representative microscopy images of $\mathrm{TLR}^{-}$4T1 and TLR5 ${ }^{+} 4 \mathrm{~T} 1$ tumor sections $(5-\mu \mathrm{m}$-thick) stained with H\&E (100x and 400x magnification) and immunohistochemically stained for TLR5 (200x and 400x magnification) (Fig. 7b, d). Staining with H\&E showed typical changes in tumor tissues. The surface and cytoplasm of tumor cells were immunohistochemically stained brown indicating TLR5 positivity. The ratio of positively stained tumor cells was much higher for TLR $5^{+} 4 \mathrm{~T} 1$ than for TLR5 ${ }^{-} 4 \mathrm{~T} 1$ tumors $(n=5 ; 68.75 \pm 5.25 \%$ vs. $20.65 \pm$ $5.65 \%, P<0.01)$.

\section{Discussion}

This study showed that TLR5 downregulation prompted TNBC proliferation, metastasis, and invasion, in vitro 

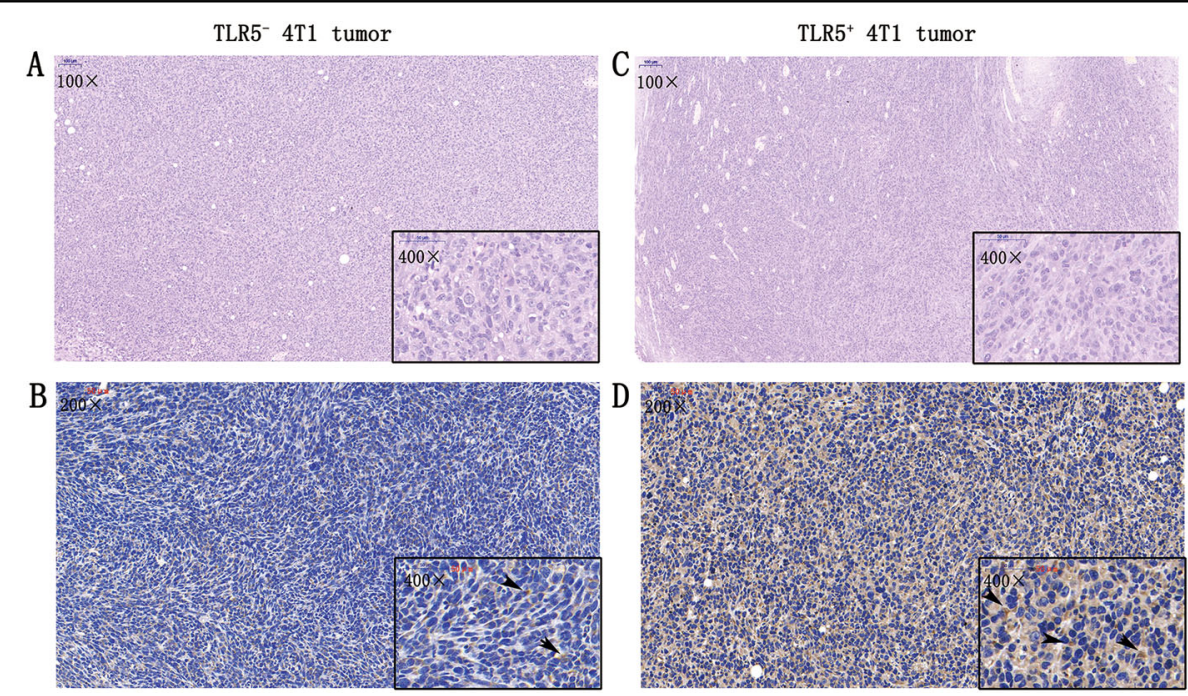

Fig. 7 H\&E staining and immunohistochemistry staining. For TLR5 ${ }^{-} 4 \mathrm{~T} 1$ tumors, representative microscopy images H\&E (a) and immunohistochemistry staining for TLR5 (b), black arrow refers to the positive area (brown) (a). For TLR5 ${ }^{+}$tumors, representative microscopy images the H\&E staining (c) and immunohistochemistry staining for TLR5 (d), black arrow refers to the positive area (brown). $n=5$, ${ }^{* *} p<0.01$. Representative results of five independent experiments were reported. The data were presented as the means \pm SD. The data were analyzed by Student's $t$ test. ${ }^{*} P<$ $0.05,{ }^{*} P<0.01$

and in vivo. More importantly, we found that TLR5 on TNBC could potentially serve as a reporter for lower metastasis, lower invasion, and better prognosis. Our results revealed a novel target molecule for earlier TNBC detection and prognosis prediction, and this could provide the means for new strategies to monitor and predict TLR5-positive tumors.

Dynamic interactions between tumors and their microenvironments are essential for tumor growth, angiogenesis, and metastasis ${ }^{29}$. High levels of TLR5 were expressed during intestinal epithelial cell-mediated antitumor activity in a mouse xenograft model of human colon cancer $^{30}$. Our findings are consistent with these results. To understand whether the downregulation of TLR5 could promote breast cancer metastasis and invasion, we detected EMT markers and its signal pathway, TRAF6 and SOX2. The EMT represented a fatal transfer of cancer progression ${ }^{31}$. Twist1, a transcription factor, played a key role in cancer development and progression $^{32}$ and up-regulated Twist1 induced EMT and Ecadherin repression, indicating that Twist1 promoted metastasis by inducing $\mathrm{EMT}^{33}$. Using western bolt and qPCR, we found E-cadherin and TLR5 expression decreased in TLR5 ${ }^{-}$4T1 cells, whereas vimentin, fibronectin, $\mathrm{N}$-cadherin and Twist1 expression increased. The metastatic and invasive abilities of TLR $5^{-} 4 \mathrm{~T} 1$ cells were enhanced. Notably, The expression of TRAF6 and SOX2 increased, and it was reported that elevated TRAF6 expression prompted SOX2 expression ${ }^{34}$, and upregulation of SOX2 prompted tumor metastasis through EMT, in breast cancer and other kind of tumors ${ }^{35,36}$. These results might help to further understand why downregulated TLR5 expression promoted 4T1 cell proliferation, metastasis, and invasion. Our data in vitro showed that TLR5 expressed in breast cancer could serve as a reporter of cancer invasiveness.

Bioprospecting for target molecules represents a promising solution for cancer prognosis ${ }^{37,38}$. TNBC is associated with aggressive tumor behavior and a worse prognosis $^{39}$. However, the early discovery of TNBC is particularly important, since its onset, early metastasis, and aggressive invasiveness is coupled with a lack of targeted therapy ${ }^{40-42}$. Therefore, identifying novel targets that closely correlate with TNBC progression is of considerable importance for its monitor and prognosis.

We previously correlated TLR5 expression with allotransplant rejection ${ }^{28}$. The expression of TLR5 in NK cells from patients with breast cancer has recently been discovered $^{43}$, and TLR5 expression could restrain tumor growth and metastasis in vitro and in vivo ${ }^{44}$. Based on these findings, we postulated that TLR5 in TNBC cells might play an important role in the progression of TNBC and serve as a novel target suitable for early TNBC monitor and prediction.

Targeted radioimmunoimaging with monoclonal antibodies against many kinds of cancers has been success$\mathrm{ful}^{24}$. Radiolabeled ${ }^{125} \mathrm{I}$-antiTLR5 $\mathrm{mAb}$ might provide a means of visualizing TLR5 expression in vivo. Our data suggested that ${ }^{125} \mathrm{I}$-antiTLR $5 \mathrm{mAb}$, which is clinically relevant, can be used in TNBC tumor models.

Our results in vitro indicated that TLR5 in TNBC was closely associated with cell invasion, but whether the same 
behavior retained in vivo remains unknown. We therefore established a xeno-subcutaneous tumor model using nude mice, then monitored with an ${ }^{125}$ I-labeled anti-TLR5 mAb tracer, which was with high affinity for TLR5 in $4 \mathrm{~T} 1$ cells in vitro. The distribution in vitro and results of whole-body phosphor-autoradiography in vivo revealed much higher radiotracer retention in TLR $5^{+} 4 \mathrm{~T} 1$ than in $\mathrm{TLR}^{-}{ }^{4} \mathrm{~T} 1$ tumors at all time points. The ${ }^{125} \mathrm{I}$-antiTLR5 $\mathrm{mAb}$ could not target $\mathrm{TLR} 5^{+} 4 \mathrm{~T} 1$ tumor in group of preinjecting unlabeled anti-TLR5 $\mathrm{mAb}$, and tumors were not visualized by radiography, thus, confirming the specificity of ${ }^{125}$ I-antiTLR $5 \mathrm{mAb}$ imaging.

Fluorescent reporter gene imaging in vivo has been applied to detect the growth and migration of labeled cells in many kinds of diseases ${ }^{45}$. Here, we monitored tumor locations using a TLR5 knockdown 4T1 cell line labeled with green fluorescent protein. The fluorescence images of virus-transfected $4 \mathrm{~T} 1$ tumors were much clearer than those of non-transfected 4T1 tumors. Moreover, this method had the advantage of clearly displaying tumor margins. More importantly, we found that locations of fluorescence emission contained more tracer radioactivity in $\mathrm{TLR}^{+}$4T1 tumor, which further confirmed that tumor imaging was TLR5 expression-specific. Additionally, early images showed the TLR5 ${ }^{-}$4T1 tumors were larger than TLR $5^{+}$4T1 tumors, which suggested that TLR5 expression might inhibit tumor growth in vivo.

To confirm that TLR5 affects tumor metastasis, we established lung metastasis mouse models by injecting $\mathrm{TLR}^{+} 4 \mathrm{~T} 1$ and $\mathrm{TLR}^{-}$4T1 cells via tail veins, and evaluated the findings using fluorescence imaging. The results showed much clearer lung tumors in $\mathrm{TLR} 5^{-}$4T1 group than in $\mathrm{TLR} 5^{+} 4 \mathrm{~T} 1$ group, suggesting that TLR5 negatively affected TNBC metastasis.

These data suggested that TLR5 expressed in breast cancer could be considered as a biomarker in vivo for the noninvasive molecular imaging of TNBC. It could also be used to monitor tumor development and metastasis, predict its prognosis, evaluate therapy responses, and as a target for therapy. Low tracer uptake in the lungs and heart, and high uptake in tumors increased image contrast. These cell-specific and favorable non-target clearance features of ${ }^{125} \mathrm{I}$-antiTLR5 $\mathrm{mAb}$ rendered it a promising radiotracer for TNBC imaging.

This study had some limitations. The molecular weight of labeled antibodies was too high for clinical applications. This might be overcome by reducing extended circulation by selecting antibody fragments, adapters, or other small molecules that specifically bind to TLR5. A radioisotopelabeled TLR5-targeting probe suitable for clinical application, such as iodine 131 or the positron nuclide Fluoro18 , should be further investigated. Hence, additional analyses of TLR 5 on breast cancer in vitro and in vivo are required.
In conclusion, the downregulation of TLR5 in TNBC increased tumor invasiveness and EMT expression and promoted TNBC metastasis. Therefore, TLR5 might be useful for monitoring and evaluating TNBC prognosis and serve as a novel target for the early detection of TNBC and other TLR5-positive tumors. The radioisotopelabeled probe, ${ }^{125} \mathrm{I}$-antiTLR5 $\mathrm{mAb}$, could potentially serve as an ideal noninvasive monitoring agent for TLR5positive tumors.

\section{Acknowledgements}

This study was supported by grants from the National Natural Science Foundation of China (81371601, to G.H.) and the Natural Science Foundation of Shandong Province (ZR2019MH019, to G.H.)

Conflict of interest

The authors declare that they have no conflict of interest.

\section{Publisher's note}

Springer Nature remains neutral with regard to jurisdictional claims in published maps and institutional affiliations.

Supplementary Information accompanies this paper at (https://doi.org/ 10.1038/s41419-019-2187-8).

Received: 17 September 2019 Revised: 3 December 2019 Accepted: 4 December 2019

Published online: 18 December 2019

\section{References}

1. Akira, S. Toll-like receptor signaling. J. Biol. Chem. 4, 38105-38108 (2003).

2. Jie-Jie, S. et al. Activation of toll pathway is different between kuruma shrimp and Drosophila. Front. Immunol. 8, 1151 (2017).

3. Cyktor, J. C. \& Mellors, J. W. Toll-like receptor agonists: can they exact a toll on human immunodeficiency virus persistence? Clin. Infect. Dis. 64, 1696-1698 (2017).

4. Krieg, A. M. \& Vollmer, J. Toll-like receptors 7, 8, and 9: linking innate immunity to autoimmunity. Immunological Rev. 220, 251-269 (2010).

5. Kluwe, J., Mencin, A. \& Schwabe, R. F. Toll-like receptors, wound healing, and carcinogenesis. J. Mol. Med. 87, 125-138 (2009).

6. Rakoff-Nahoum, S. \& Medzhitov, R. Toll-like receptors and cancer. Nature Rev. Cancer 9, 57-63 (2008).

7. Lin, L. L. et al. Downregulation of C-Myc is involved in TLR3-mediated tumor death of neuroblastoma xenografts. Lab. Investig. 96, 719-30 (2016).

8. lotzova-Weiss, G. et al. TLR4 as a negative regulator of keratinocyte proliferation. PLOS ONE 12, e0185668 (2017).

9. Cai et al. Activation of toll-like receptor 5 on breast cancer cells by flagellin suppresses cell proliferation and tumor growth. Cancer Res. 71, 2466-2475 (2011).

10. Zhou et al. Expression of TLR5 in different types of non-small cell lung cancer cell lines and its activation mechanism. Chin. J. Lung Cancer 18, 8-15 (2015).

11. Shuang, $\mathbf{C}$. et al. Toll-like receptor 5 gene polymorphism is associated with breast cancer susceptibility. Oncotarget 8, 88622-88629 (2017).

12. Burdelya, L. G. et al. Central role of liver in anticancer and radioprotective activities of Toll-like receptor 5 agonist. Proc. Natl Acad. Sci. 110, E1857-E1866 (2013).

13. Li, W. et al. CBLB502, an agonist of toll-like receptor 5, has antioxidant and scavenging free radicals activities in vitro. Int. J. Biol. Macromol. 82, 97-103 (2015).

14. O"Neill, L. A. J., Bryant, C. E. \& Doyle, S. L. Therapeutic targeting of toll-like receptors for infectious and inflammatory diseases and cancer. Pharmacol. Rev. 61, 177-197 (2009).

15. Akram, M., lqbal, M., Daniyal, M. \& Khan, A. U. Awareness and current knowledge of breast cancer. Biol. Res. 50, 33 (2017). 
16. Eniu, A. et al. Guideline implementation for breast healthcare in low- and middle-Income countries: Treatment resource allocation. Cancer $\mathbf{1 1 3}$ 2269-2281 (2008).

17. Siegel, R., Naishadham, D. \& Jemal, A. Cancer statistics, 2013. CA Cancer J. Clin 63, 11-30 (2013).

18. Joyce, D. P. et al. Prospective comparison of outcome after treatment for triple-negative and non-triple-negative breast cancer. Surgeon 15, 272-277 (2016).

19. Bertozzi, N., Pesce, M., Santi, P. L. \& Raposio, E. Oncoplastic breast surgery: comprehensive review. Eur. Rev. Med. Pharmacol. Sci. 21, 2572-2585 (2017).

20. Majumder, S. \& Chari, S. T. Chronic pancreatitis. Wiadomosci Lekarskie 387, 1957-1966 (2016).

21. Ou, X. et al. Ability of ${ }^{18}$ F-FDG PET/CT radiomic features to distinguish breast carcinoma from breast lymphoma. Contrast Media Mol. Imaging 2019, 4507694 (2019).

22. Wang, D. et al. Long noncoding RNA CCAT2 as a novel biomaker of metastasis and prognosis in human cancer: a meta-analysis. Oncotarget 8, 75664-75674 (2017).

23. Peng, F. et al. Identification of a three miRNA signature as a novel potential prognostic biomarker in patients with bladder cancer. Oncotarget 8, 105553-105560 (2017).

24. Jhan, J. R. \& Andrechek, E. R. Triple-negative breast cancer and the potential for targeted therapy. Pharmacogenomics 18, 1595-1609 (2017).

25. Kim, H. J. et al. PET imaging of HER2 expression with an ${ }^{18} \mathrm{~F}$-fluoride labeled aptamer. PLOS ONE 14, e0211047 (2019).

26. You, L., Wang, X. \& Guo, Z. MicroSPECT imaging of triple negative breast cancer cell tumor xenografted in athymic mice with radioiodinated anti-ICAM1 monoclonal antibody. Appl. Radiat. Isot. 139, 20-25 (2018).

27. Henry, K. E. et al. Non-invasive ${ }^{89} \mathrm{Zr}$-transferrin PET shows improved tumor targeting compared to ${ }^{18} \mathrm{~F}$-FDG PET in MYC-overexpressing human triple negative breast cancer. J. Nucl. Med. Off. Publ. Soc. Nucl. Med. 59, 51-57 (2017).

28. Sun, $\mathrm{H}$. et al. Non-invasive imaging of allogeneic transplanted skin graft by 1311-anti-TLR5 mAb. J. Cell. Mol. Med. 18, 2437-2444 (2014).

29. Mantovani, A., Allavena, P., Sica, A. \& Balkwill, F. Cancer-related inflammation. Nature 454, 436-444 (2008).

30. Rhee, S. H., Im, E. \& Pothoulakis, C. Toll-like receptor 5 engagement modulates tumor development and growth in a mouse xenograft model of human colon cancer. Gastroenterology 135, 518-528 (2008).

31. Wang, N. et al. miR520c blocks EMT progression of human breast cancer cells by repressing STAT3. Oncol. Rep. 37, 1537-1544 (2017).
32. Zhao, Z., Rahman, M. A., Chen, Z. G. \& Shin, D. M. Multiple biological functions of Twist1 in various cancers. Oncotarget 8, 20380-20393 (2017).

33. Yuan, W. et al. Knockdown of CMTM3 promotes metastasis of gastric cance via the STAT3/Twist1/EMT signaling pathway. Oncotarget 7, 29507-29519 (2016).

34. Chen, L. et al. TRAF6 regulates tumour metastasis through EMT and CSC phenotypes in head and neck squamous cell carcinoma. J. Cell Mol. Med 22, 1337-1349 (2018).

35. Liu, X. et al. Sox2 promotes tumor aggressiveness and epithelial-mesenchymal transition in tongue squamous cell carcinoma. Int. J. Mol. Med. 42, 1418-1426 (2018).

36. Wang, Y., Zhou, J., Wang, Z., Wang, P. \& Li, S. Upregulation of SOX2 activated LncRNA PVT1 expression promotes breast cancer cell growth and invasion Biochem. Biophys. Res. Commun. 493, 429-436 (2017).

37. Wang, D. et al. Long noncoding RNA CCAT2 as a novel biomaker of metastasis and prognosis in human cancer: a meta-analysis. Oncotarget 8, 75664-75674 (2017).

38. van Dongen, G. A., Visser, G. W., Lub-de Hooge, M. N., de Vries, E. G. \& Perk, L. R. Immuno-PET: a navigator in monoclonal antibody development and applications. Oncologist 12, 1379-1389 (2007).

39. Agarwal, G. et al. Outcomes of triple-negative breast cancers (TNBC) compared with non-TNBC: does the survival vary for all stages? World J. Surg. 40 1362-1372 (2016)

40. Wein, L. \& Loi, S. Mechanisms of resistance of chemotherapy in early-stage triple negative breast cancer (TNBC). Breast 34, 27-30 (2017).

41. Rampurwala, M. Wisinski, K. B. \& Ruth, O. R. Role of the androgen receptor in triple-negative breast cancer. Clin. Adv. Hematol. Oncol. H. O 14, 186-193 (2016).

42. Narrandes, S., Huang, S., Murphy, L. \& Xu, W. The exploration of contrasting pathways in Triple Negative Breast Cancer (TNBC). BMC Cancer 18, 22 (2018).

43. Brackett, C. M. et al. Toll-like receptor-5 agonist, entolimod, suppresses metastasis and induces immunity by stimulating an NK-dendritic-CD8 ${ }^{+}$T-cell axis. Proc. Natl Acad. Sci. USA 113, E874-E883 (2016).

44. Zhou, $\mathrm{H}$. et al. High expression of Toll-like receptor 5 correlates with better prognosis in non-small-cell lung cancer: an anti-tumor effect of TLR5 signaling in non-small cell lung cancer. J. Cancer Res. Clin. Oncol. 140, 633-643 (2014)

45. Ogawa, M. \& Takakura, H. In vivo molecular imaging for biomedical analysis and therapies. Anal. Sci. 34, 273-281 (2018). 